\title{
Philosophical Implications of Theory of Affordances
}

\author{
Hiroshi YochI
}

\section{Introduction}

The studies related to affordances have been developing in connection with theories of situated action. Originally, the researches on affordances has been established in the field of psychology by James J. Gibson and his adherents. Theory of direct perception presented by Gibson seems to drive philosophers to revisits to the philosophies of Whitehead, Dewey, Bergson, Husserl, Merleau-Ponty, etc. On the other hand, the results of Gibsonians' researches have been extended to social action theories beyond Gibson's intention. These social action theories have the same disposition as Searle's speech acts theory, Garfinkel's ethnomethodology, Vygotsky's cultural-historical theory and activity theory, etc., which deal with language as one of the artifacts. Thus the concept affordances has been also extended and applied to the artifacts such as daily instruments, language and institution. This extension might raise the interrelationship among thoughts given by Wittgenstein, Bourdieu, Foucault, Bakhtin, Heidegger, etc.

This paper, at first, outlines the stance of theory of affordances. Secondly, in relation to theory of direct perception in Gibsonian ecological approach, the philosophies of Whitehead and Dewey are revisited, especially from the viewpoint of experience. This process would give philosophical foundations to Gibson's system, conversely, in spite of Gibson's excluding philosophy. Thirdly, social action theories which the extended theories of affordances would imply are related to the philosophies of Wittgenstein, Dewey, Bourdieu, Bakhtin, etc. There rises the problem of subjectivity in social interactions. This paper introduces Magoroh Maruyama's conceptual framework of mindscapes, which describes the types of interactions, as a solution to the problem of subjectivity.

\section{Significance of Theory of Affordances}

The term "affordances" was coined by James J. Gibson [1]. It is defined as the invitational quality of a percept or an event (Reber (1995: 16)), for example. Thus, a part of the affordance of a hammer affords hitting and a part of the affordance of a chair affords sitting. Gibson says, "they [affordances] are ecological, in the sense that they are properties of the environment relative to an animal." (Reed

Hospital Computer Center, The University of Tokyo Hospital 
\& Jones (1982: 404)) So affordances are not simply phenomenal qualities of subjective experience and they are not simply the physical properties of things as conceived by physical science (Reed \& Jones (1982: 404)). Affordances have not only the positive valences of things but also the negative valences (Reed \& Jones (1982: 405-406)). For example, a fire affords warmth, but also affords being burned. Thus, a thing affords something, and we perceive or learn to perceive it (cf. Reed \& Jones (1982: 406)).

According to Gibson's theoretical position of direct perception, we learn about the world by direct pickup of information about the invariant properties of the environment (Reber (1995: 315)). Here, the next two points characterize the Gibson's ecological system (Reber (1995: 315), Reed \& Jones (1982 : 408)) :

(1) Raw sensations are not required. In other words, we no longer have to assume that there is a sensation-based perception of a thing.

(2) Internal organizing and inference systems that structure and code the sensations are not required. In other words, we no longer have to assume that there is the accrual of meaning to the primary percept (the "enrichment" theory of perception, based on innate sensations and acquired images).

Gibson's position contrasts with constructivism. The so-called frame problem also gives the positive evidences that the constructivism is unsupportable. Our behavior is in terms of stimulus information, not of stimuli (Reed \& Jones (1982: 406)). In psychological thought, what a thing is has been regarded as being physical and what it means has been regarded as being mental. The affordances give up such a dichotomy. The perception of what a thing is and the perception of what it means are not separate. For example, to perceive that a surface is level and solid is also to perceive that it is walk-on-able (Reed \& Jones (1982: 408)). Gibson pays regard to Berkeley's theory of visual perception (cf. Reed \& Jones (1982: 13)), so Gibson might have taken into account the realization of Berkeley's thesis esse est percipi (Tanaka (1998: 217-218)). To the contrary, Locke listed the primary qualities and the secondary qualities, and Descartes determined to integrate physics and psychology by means of the doctrine of primary and secondary qualities (Reed \& Jones (1982: 401)). The theory of affordances breaks the Cartesian spell.

Educated adults have a conception of space, that is, mathematical space, Euclidean, Cartesian, non-Euclidean, etc. However, Gibson says, "Animals, and children until they learn theoretical geometry, pay attention to the affordances of layout rather than the mathematics of layout. Hence, although logically one advances from space to affordance, developmentally the progress is the opposite direction, from affordance to space." (Reed \& Jones (1982: 407)) In this way, the 
properties of the environment should be taken from concepts of ecology instead of from mathematics and physics (Reed \& Jones (1982: 401-403)) :

Spatial properties; We do not visually perceive "space," but we do perceive the persisting, that is, relatively invariant, properties of the world.

Spatio-Temporal properties; We do not perceive "time" as such, but we do perceive changes or varying properties of the world, which are spatiotemporal.

Thus, "abstract" objects do not exist. There are, to be sure, realities that cannot be perceived directly but only known indirectly by means of instruments, measuring operations, pictures, and language, but it is mistaken to call such realities "abstract" as against "concrete." (Reed \& Jones (1982: 417)) In addition, we proprioceive as well as perceive. We should note that we can detect the characteristics of "the self as the center of the environment" (Reed \& Jones (1982: 403)), who directly extracts the information about the invariant properties of the environment. Gibson also refers to the problem of subjectivity, but his discussion is uncertain. "What about so-called "subjective" reality? Awareness of the persisting and changing environment (perception) is concurrent with the complementary awareness of the persisting and changing self (proprioception...). This includes the body and its parts, and all its activities, from locomotion to thought... Oneself and one's body exist along with the environment. They are co-perceived. They are inescapable in the environment at the place called here. ... One's nose, hands, feet, heart, and stomach are co-perceived; and so one's pains and itches and the aftereffects of stimulation ...; and so are one's ideas, insights, fantasies, dreams, and memories of childhood." (Reed \& Jones (1982: 418))

In this section, the theories of affordances and direct perception have been summarized, in preparation for the following philosophical arguments. Thus the theories might be extended as follows: "much of our everyday knowledge resides in the world, not in the head." (Norman (1988: ix))

\section{Philosophical Foundations for Gibson's System}

\subsection{Dewey on Direct Perception and Affordances}

J.J. Gibson is said to have been affected by John Dewey's pragmatism (Saito (1994: 333)). The very title of one of Dewey's chief books is Experience and Nature. Dewey says, "To many the associating of the two words will see like talking of a round square." (Dewey (1929: 1)) Dewey intended to signify that his philosophy may be termed either empirical naturalism or naturalistic empiricism, or naturalistic humanism (Dewey (1929: 1)). In the philosophy of Dewey, "Experi- 
ence is a matter of the interaction of organism with its environment, an environment that is human as well as physical, that includes the materials of tradition and institutions as well as local surroundings. The organism brings with it through its own structure, native and acquired, forces that play a part in the interaction." (Dewey (1934: 246), Saito (1994: 320)) Dewey also says, "... experience is of as well as in nature. It is not experience which is experienced, but nature - stones, plants, animals, diseases, health, temperature, electricity, and so on. Things interacting in certain ways are experience; they are what is experienced. Linked in certain other ways with another natural object - the human organism - they are how things are experienced as well." (Dewey (1929:4)) So, "Experience thus reaches down into nature ; it has depth. It also has breadth and to an indefinitely elastic extent. It stretches. That stretch constitutes inference." (Dewey (1929:4)) The above citation might correspond to the two points (1) and (2) which characterize the Gibson's ecological system. Here, we should note that Dewey posits the logic in the world, not in the head [2].

The following citation seems to correspond to theories of direct perception and affordances. "... it [the optical apparatus] never functions in isolation. It operates in connection with the hand in reaching for things and in exploring their surface, in guiding manipulation of things, in directing locomotion." (Dewey (1934 : 100), Saito (1994: 327)) For things in nature, "The roundness seen is that of balls ; angles perceived are the result not just of switches in the eye-movements but are properties of books and boxes handled; curves are the arch of the sky, the dome of a building; horizontal lines are seen as the spread of the ground, the edges of things around us. ... Nature, in other words, does not present us with lines in isolation." (Dewey (1934: 100), Saito (1994: 324-325)) So, "what is perceived are meanings, rather than just events or existences." (Dewey (1929: 258)) Dewey also refers to Berkeley, "If we say sensible knowledge is the genuine, then we are committed to phenomenalism of a somewhat chaotic kind, unless we follow Berkeley and invoke deity to hold the immediate things together." (Dewey (1929: 117))

According to Dewey, "Experience occurs continuously, because the interaction of live creature and environing conditions is involved in the very process of living. Under conditions of resistance and conflict, aspects and elements of the self and the world that are implicated in this interaction qualify experience with emotions and ideas so that conscious intent emerges." (Dewey (1934: 35)) However, Dewey does not regard such experience as an experience. We have an experience when the experienced material runs its course to fulfillment (Dewey (1934: 35)). So, "Such an experience is a whole and carries with it its own individualizing quality and self-sufficiency." (Dewey (1934: 35)) And, "For to perceive, a beholder must create his own experience." (Dewey (1934: 54), Saito (1994:327)) This is Dewey's reference to subjectivity. Thus, "Things in the environment... become means, 
media." (Dewey (1934: 60), Saito (1994: 326))

As to space and time, Dewey says, "Movement in direct experience is alteration in the qualities of objects, and space as experienced is an aspect of this qualitative change." (Dewey (1934: 207))

In this section, the correspondence of Gibson's system to the philosophy of Dewey has been attempted. Gibson's results call the attention to the philosophy of Dewey, and Dewey's thought is more than Gibson's suggestion. Dewey justifies the functioning of experience in the scientific inquiries. "These remarks are not supposed to prove anything about experience and nature for philosophical doctrine; they are not supposed to settle anything about the worth of empirical naturalism. But they do show that in the case of natural science we habitually treat experience as starting-point, and as method for dealing with nature, and as the goal in which nature is disclosed for what it is." (Dewey (1929: 4-5))

\subsection{Whitehead on Direct Perception and Affordances}

The philosophy of Whitehead does not expressively correspond to Gibson's theories of direct perception and affordances. But notionally, Whitehead's philosophy has the same disposition as Gibson's theories. Here, of Whitehead's philosophy, chiefly, the period of philosophy of science is dealt with, and the period of metaphysics is dealt with only in the extended context.

Whitehead says, "We look up and see a coloured shape in front of us, and we say, - there is a chair. But what we have seen is the mere coloured shape. Perhaps an artist might not have jumped to the notion of a chair. He might have stopped at the mere contemplation of a beautiful colour and a beautiful shape. But those of us who are not artists are very prone, especially if we are tired, to pass straight from the perception of the coloured shape to the enjoyment of the chair, in some way of use, or of emotion, or of thought. ... my friend the artist, who kept himself to the contemplation of colour, shape and position, was a very highly trained man, and had acquired this facility of ignoring the chair at the cost of great labour. We do not require elaborate training merely in order to refrain from embarking upon intricate trains of inference." (Whitehead (1927:2-3)) This exemplifies Whitehead's so-called presentational immediacy.

According to Whitehead, there are two modes of direct perception of the external world. One perceptive mode is presentational immediacy, and the other mode causal efficacy. The mode of causal efficacy functions on the time in the concrete. "Time in the concrete is the conformation of state to state, the later to the earlier..." (Whitehead (1927: 35)) So, "In the mode of causal efficacy they [the sense-data] exhibit the almost instantaneously precedent bodily organs as imposing their characters on the experience in question. We see the picture, and we see it with our eyes; we touch the wood, and we touch it with our hands ; ..." (White- 
head (1927: 50)) This might correspond to the two points (1) and (2) which characterize the Gibson's ecological system because "direct perception is antecedent to thought about it." (Whitehead (1927: 39)) From the different viewpoint, "The sense-data, required for immediate sense-perception, enter into experience in virtue of the efficacy of the environment." (Whitehead (1927: 52))

In this way, Whitehead's notion of symbolism seems to correspond to the theory of affordances. Whitehead says, "... coloured shapes seem to be symbols for some other elements [e.g. a chair] in our experience, and when we see the coloured shapes we adjust our actions towards those other elements. ... Symbolism from sensepresentation to physical bodies is the most natural and widespread of all symbolic modes." (Whitehead (1927: 4)) According to Whitehead's definition of symbolism, "The human mind is functioning symbolically when some components of its experience elicit consciousness, beliefs, emotions, and usages, respecting other components of its experience. The former set of components are the 'symbols,' and the latter set constitute the 'meaning' of the symbols. The organic functioning whereby there is transition from the symbol to the meaning will be called 'symbolic reference."' (Whitehead (1927: 7-8)) Thus, "... symbolic reference is the active synthetic element contributed by the nature of the percipient." (Whitehead (1927:8)) Symbolic reference is called 'significance' in the earlier period of Whitehead's philosophy. Then, direct experience is infallible, but symbolism is very fallible (Whitehead (1927:6)). From this point, the philosophy of Berkeley is justified: "Berkeley himself insists that experience is significant,... But Kant's position is the converse of Berkeley's, namely that significance is experience. Berkeley first analyses experience, and then expounds his view of its significance,... For Berkeley the significance is detachable from the experience." (Whitehead (1925 : 1112)) Symbolism is arbitrary.

Again, let us refer to the spatio-temporal relationship between the percipient and the things perceived. "Objects enter into experience by recognition and without recognition experience would divulge no objects. Objects convey the permanences recognised in events, and are recognised as self-identical amid different circumstances; that is to say, the same object is recognised as related to diverse events. Thus the self-identical object maintains itself amid the flux of events : it is there and then, and it is here and now..." (Whitehead (1925:62-63)) Whitehead says, "... natural knowledge is a knowledge from within nature, a knowledge 'here within nature' and 'now within nature,' and is an awareness of the natural relations of one element in nature (namely, the percipient event) to the rest of nature. Also what is known is not barely the things but the relations of things, and not the relations in the abstract but specifically those things as related." (Whitehead (1925: 13)) So, "... we see it [the colour green] somewhere in space related to our eyes at a certain epoch of our bodily life." (Whitehead (1922 : 24-25)) 
In his metaphysics, Whitehead introduces new notions. According to Whitehead, the actual world is a process, and the process is the becoming of 'actual entities.' Every 'prehension' consists of three factors: (a) the 'subject' which is prehending, namely, the actual entity in which that prehension is a concrete element; (b) the 'datum' which is prehended; (c) the 'subjective form' which is how that subject prehends that datum. There are two species of prehensions: (a) 'positive prehensions' which are termed 'feelings', and (b) 'negative prehensions' which are said to 'eliminate from feeling.' Negative prehensions also have subjective forms. A negative prehension holds its datum as inoperative in the progressive concrescence of prehensions constituting the unity of the subject (Whitehead (1978: 22-24)). In this sense, Whitehead accepts 'subjectivist principle' (cf. Whitehead (1978: Chap. VII, Sec. V)). Whitehead's philosophy is beyond the dichotomy between subjectivism and objectivism. "The individual enjoyment is what I am in my role of a natural activity, as I shape the activities of the environment into a new creation, which is myself at this moment; and yet, as being myself, it is a continuation of the antecedent world. If we stress the role of the environment, this process is causation. If we stress the role of my immediate pattern of active enjoyment, this process is self-creation. If we stress the role of the conceptual anticipation of the future..., this process is the teleological aim at some ideal in the future." (Whitehead (1968: 166), Ichii (1980:142-143))

In this section, the correspondence of Gibson's system to the philosophy of Whitehead has been attempted. Gibson's results might justify Whitehead's notion of symbolism, and Whitehead's so-called integrated naturalism might give Gibsonians a good perspective. Whitehead's stance appears symbolically in the divorce between him and Russell concerning the fourth volume of Principia Mathematica. Russell writes, "When two relation-numbers are ordinally similar, we can say that they generate the same 'structure', but structure is a somewhat more general conception than this since it is not confined to ... relations between two terms. Relations between three or between four terms are important in geometry, and Whitehead was to have dealt with them in the fourth volume of the Principia, but, after he had done a lot of the preliminary work, his interest flagged and he abandoned the enterprise for philosophy. It is, however, fairly easy to see how the conception of structure can be generalised..." (Russell (1995: 75)) Whitehead positions his own stance as follows: "For Kant, the world emerges from the subject; for the philosophy of organism, the subject emerges from the world - a 'superject' rather than a 'subject."” (Whitehead (1978: 88)) 


\section{From Theory of Affordances to Social Action Theory}

\subsection{Extended Theory of Affordances}

Beyond Gibson's intention, theory of affordances has been extended to social action theory, including distributed cognition and situated action. It is a subject who has cognition, but its cognition is realized in the system with the subject as a part of its system rather than in the head of isolated subject. We have cognition without using our heads so much, by means of using the characteristics of instruments. And we transfer our memories to external symbolic systems. In addition, communication with each other enables us to have higher cognition that isolated subject could not have (cf. Nishiyama (1997)). These instruments and symbolic systems form affordances in the extended context. Thus affordances have been extended and applied to the artifacts in general such as daily instruments, language and institution.

Let us observe everyday life in kitchen, supermarkets, workshop and so on. We structure environments surrounding ourselves. Thus, inferences, memories, perception, etc. are embedded as instruments in the environments, and are rather simplified. We, as the active with bodies, are in contact with environments, have diverse embedded cognitive activities in the environments and organize ourselves in connection with the environments (Kimura (1996: 13)). So, this situation is beyond subjectivism and objectivism, because we are influenced by the structured environments conversely. Cognitive anthropology has developed this research field (Kimura (1996), Bourdieu (1984,1990), Chaiklin and Lave (1993), etc.). The investigations into the structured environments connect themselves with the finding of symbolic classifications (cf. R. Needham (1981), Bourdieu (1984, 1990)). And these classifications are to found on the basis of "family resemblances" (Wittgenstein (1958: Part I, §66, §67), R. Needham (1981), Teranaka (1987)).

These social action theories have the same disposition as Searle's speech acts theory, Garfinkel's ethnomethodology, Vygotsky's cultural-historical theory and activity theory, etc., which deal with language. If people's activities are creative, their language must be dialogical, not monological, in the sense of Bakhtin's social poetics (Shotter $(1995,1998)$ ). Searle says, "One of the things we need to recognize about conversations is that they involve shared intentionality." (Searle (1992: 21), Shotter (1995)) So, we come to pay attention to others and society. Bakhtin describes, "It is fully understandable that at the center of Dostoevsky's artistic world must lie dialogue, and dialogue not as a means but as an end in itself. Dialogue here is not the threshold to action, it is the action itself. ... in dialogue a person not only shows himself outwardly, but he comes for the first time that which he is ... not only for others but for himself as well. To be means to communicate dialogically. When dialogue ends, everything ends. Thus dialogue, by its very 
essence, cannot and must not come to an end." (Bakhtin (1984: 252))

Vygotsky is said to have emphasized that, as mediators of human action, all artifacts can be considered tools and symbols [3]. All artifacts are historical, cultural and social. Volosinov (Bakhtin) says, "A word in the mouth of a particular individual person is a product of the living interaction of social forces." (Volosinov (1973: 41)) Thus, it is the institution that is the ultimate of all artifacts. In this context, Wittgenstein's mule-following, Bourdieu's habitus - pratique, etc. could be remembered. According to Bourdieu, "The habitus - embodied history, internalized as a second nature and so forgotten as history - is the active presence of the whole past of which it is the product." (Bourdieu (1990:56)) And, "The cognitive structures which social agents implement in their practical knowledge of the social world are internalized, 'embodied' social structures. The practical knowledge of the social world... implements classificatory schemes (or 'forms of classification', 'mental structures' or 'symbolic forms' - apart from their connotations, these expressions are virtually interchangeable), historical schemes of perception and appreciation which are the product of the objective division into classes (age groups, genders, social classes) and which function below the level of consciousness and discourse." (Bourdieu (1984: 468)) This stance on studies is also seen in the revisits to T.B. Veblen and Institutionalism in economics (cf. Nishiyama (1997)), and Graham Wallas, Hannah Arendt, etc. in politics.

In this section, we have seen that affordances are extended to instruments, language, institution and so on in social context.

\subsection{The Problem of Subjectivity in Social Interactions}

We could conclude that the opposition between subjectivism and objectivism is to be given up on the above considerations. However, we are not contented somehow. Why?

According to Dewey, "Individuality itself is originally a potentiality and is realized only in interaction with surrounding conditions. In this process of intercourse, native capacities, which contain an element of uniqueness, are transformed and become a self. Moreover, through resistances encountered, the nature of the self is discovered." (Dewey (1934: 281-282), Saito (1994: 326)) And, "It is when the desires and aims, the interests and modes of response of another become an expansion of our own being that we understand him. We learn to see with his eyes, hear with his ears, and their results give true instruction, for they are built into our own structure." (Dewey (1934: 336), Saito (1994: 329)) Thus, the subject is what is formed. However, in the actual world, how can " $I$ " be what is in the other positions? If "I" cannot be, there might be the power by the other. This situation is monological, in Bakhtin's terms, which is one-sided and one-way (Shotter (1998)). To be dialogical, we need the realization of polyphony. Bakhtin says, "the utterly 
incompatible elements comprising Dostoevsky's material are distributed among several worlds and several autonomous consciousnesses; they are presented not within a single field of vision but within several fields of vision, each full and of equal worth; and it is not the material directly but these worlds, their consciousnesses with their individual fields of vision that combine in a higher unity, a unity, so to speak, of the second order, the unity of a polyphonic novel. ... Thanks to these various worlds the material can develop to the furthest extent what is most original and peculiar in it, without disturbing the unity of the whole and without mechanizing it." (Bakhtin (1984: 16))

Magoroh Maruyama presents mindscapes which mean structures of reasoning, cognition, perception, conceptualization, design, planning, and decision making that may vary from one individual, profession, culture, or social group to another (Maruyama (1980)). There are four types of mindscapes: H, I, S and G.

$\mathrm{H}$ type : Its components are homogenistic. Its relation between homogenistic components is $[\mathrm{H}]$ ierarchical. Its mode is classificational.

I type : Its components are heterogenistic. But its relation between components is [I] ndividualistic. Its mode is random.

$\mathrm{S}$ type : Its components are heterogenistic. Its relation between components is interactive. But its mode is homeo[S]tatic.

G type : Its components are heterogenistic. Its relation between components is interactive. Its mode is morpho[G]enetic.

Here, $\mathrm{H}$ and $\mathrm{I}$ are monological in Bakhtin's terms. $\mathrm{S}$ is dialogical but not polyphonic because its mode might be deterministic. When we take $G$ type, we can be in the different positions to each other and ourselves. Otherwise, we fall into estrangement from ourselves.

Maruyama's mindscapes might content us as a solution to the problem of subjectivity in social interactions.

Monological stance brings us the authorized world in the heads. On the other hand, dialogical stance brings us the living world mediated by language as one of affordances. Wittgenstein says, "...they [human beings] agree in the language they use. That is not agreement in opinions but in form of life." (Wittgenstein (1958: Part I, §241)) And he says, "don't think but look!" (Wittgenstein (1958: Part I, §66)) Then what does he mean?

\section{Conclusion}

In this paper we have given the philosophical foundations for theory of affordances and its extended theory. To advance theory of affordances, we require 
its philosophical foundations and perspectives. Fortunately, it has been found that the philosophies of Dewey and Whitehead could correspond to Gibson's system to some extent. On the other hand, their philosophies has received the positive evidence from Gibson's system. We must set about the working philosophy.

Cognitive anthropology and cultural psychology have unconsciously dealt with the extended theory of affordances, in the forms of distributed cognitions and situated actions. We also have given the philosophical perspectives on these fields.

As the field study that embodies polyphonic situations and G type mindscape, we must advance distributed cognitions. And Searle's speech acts theory in social context is significant.

We must seek for good affordances above all.

\section{Acknowledgments}

An earlier draft of this paper was presented under the title, "Affordances from the Viewpoint of Symbolism," at the Conference of the Japan Association for Philosophy of Science, held in June 1998. I am grateful for pointed comments and questions at the conference, for they have prompted me to this research.

\section{Notes}

[1] To be exact, there is the history of the concept of affordance. Gibson says, "The term [affordance] is reminiscent of a word coined by Kurt Lewin, Aufforderungscharakter. The term was first translated into English as invitation-character (by J.F. Brown in 1929) and later as valence (by D.K. Adams in 1931). ... Koffka invented a new term, demand-character ..." (Reed \& Jones (1982: 409))

[2] I do not intend to bring up the dispute of logic between dialectics and formal logic again.

[3] Cole \& Engeström (1993: 13-14). To be exact, Vygotsky writes, "this new activity [the process of concept formation] is mediated by signs." (Vygotsky (1986: 109))

\section{References}

Baker, G.P. and Hacker, P.M.S. (1984) Scepticism, Rules and Language. Oxford: Basil Blackwell.

Bakhtin, M. (1984) Problems of Dostoevsky's Poetics (ed. and trans. C. Emerson). Minneapolis, MN : University of Minnesota Press.

Bourdieu, P. (1984) [1979] Distinction: A Social Critique of the Judgement of Taste (trans. R. Nice). Cambridge, MA : Harvard University Press.

Bourdieu, P. (1990) [1980] The Logic of Practice (trans. R. Nice). Stanford, CA : Stanford University Press.

Chaiklin, S. and Lave, J. (eds) (1993) Understanding Practice: Perspectives on Activity and Context. Cambridge, New York and Melbourne: Cambridge University Press.

$$
-241-
$$


Cole, M. and Engeström, Y. (1993) "A Cultural-historical Approach to Distributed Cognition," in Salomon, G. (ed) Distributed Cognitions : Psychological and Educational Considerations. Cambridge, New York and Melbourne: Cambridge University Press. pp. 1-46.

Dewey, J. (1929) Experience and Nature (2nd edn). La Salle, IL : Open Court.

Dewey, J. (1958) [1934] Art as Experience. New York: G.P. Putnam's Sons.

Ichii, S. (1980) [1956] The Philosophy of Whitehead (in Japanese). Tokyo: Dai-SanBunmei Sha.

Ichikawa, Hiroshi (1975) Body as Mind (in Japanese). Tokyo: Keiso Shobo.

Ichikawa, Hiroshi (1984) The Structure of $\langle M i(B o d y)\rangle:$ Beyond Theory of Body (in Japanese). Tokyo: Seidosha.

Kimura, Tadamasa (1996) "Social Action Spaces through the Medium of Electronic Mail" (in Japanese), Nihongo Gaku, Vol. 15, No. $12:$ 12-26.

Kiso, Yoshinobu (1979) "Perceptual World" (in Japanese), in Takeo, J. (ed) Philosophy of Science, Tokyo: Hokuju Shuppan. pp. 16-40.

Lave, J. and Wenger, E. (1991) Situated Learning: Legitimate Peripheral Participation. Cambridge. New York and Melbourne : Cambridge University Press.

Maruyama, Magoroh (1980) "Mindscapes and Science Theories," Current Anthropology, 21 : $589-608$.

Needham, Rodney (1981) Circumstantial Deliveries. Berkeley and Los Angeles, CA: University of California Press.

Nishiyama, Ken-ichi (1997) "Complex Systems: Via Discoveries of Bodies toward Phenomenalism" (in Japanese), Dai Kokai (Voyages into History, Literature and Thought), No. 16: 74-82.

Norman, D.A. (1988) The Psychology of Everyday Things. New York: Basic Books.

Reber, A.S. (1995) The Penguin Dictionary of Psychology (2nd edn). Harmondsworth: Penguin Books.

Reed, E. and Jones, R. (eds) (1982) Reasons for Realism: Selected Essays of James J. Gibson. Hillsdale, NJ : Lawrence Erlbaum Associates.

Russell, B. (1995) [1959] My Philosophical Development. London and New York: Routledge.

Saito, Naoko (1994) "Interaction as Realization of "Potentiality" (in Japanese), Gendai Shiso (Reveu de la Pensée d'Aujourd'hui), Vol. 21, No. 13 : 317-333.

Searle, J.R., et al. (1992) (On) Searle on Conversation (compiled and introduced by H. Parret and J. Verschueren). Amsterdam and Philadelphia, PA : John Benjamins.

Shotter, J. (1995) "In Conversation: Joint Action, Shared Intentionality and Ethics," Theory and Psychology, Vol. 5, No. 1: 49-73.

Shotter, J. (1998) "Social Construction as Social Poetics: Oliver Sacks and the Case of Dr P," in Bayer, B.M. and Shotter, J. (eds) Reconstructing the Psychological Subject: Bodies, Practices and Technologies. London, Thousand Oaks, CA and New Delhi: Sage Publications. pp. 33-51.

Tanaka, Yutaka (1998) Whitehead: The philosophy of Organism (in Japanese). Tokyo: Kodansha.

Teranaka, Heiji (1987) "Influence on Sociology and Anthropology" (in Japanese), in Yamamoto, M. and Kurosaki, H. (eds) A Compact Encyclopedia of Wittgenstein. Tokyo: Taishukan Shoten. pp. 297-300.

Volosinov, V.N. (1973) [1930] Marxism and the Philosophy of Language (trans. L. Matejka and I.R. Titunik). New York and London: Seminar Press.

Vygotsky, L.S. (1986) [1934] Thought and Language (translation revised by A. Kozulin). Cambridge, MA : The MIT Press.

Whitehead, A.N. (1925) [1919] An Enquiry Concerning the Principles of Natural Knowl- 
edge (2nd edn). Cambridge: The University Press, Cambridge.

Whitehead, A.N. (1922) The Principle of Relativity with applications to Physical Science. Cambridge: The University Press, Cambridge.

Whitehead, A.N. (1985) [1927] Symbolism: Its Meaning and Effect. New York: Fordham University Press.

Whitehead, A.N. (1978) [1929] Process and Reality: An Essay in Cosmology (corrected edn). New York: The Free Press.

Whitehead, A.N. (1968) [1938] Modes of Thought. New York: The Free Press.

Wittgenstein, L. (1958) Philosophical Investigations (2nd edn) (trans. G.E.M. Anscombe). Oxford and Malden, MA : Blackwell.

Wittgenstein, L. (1998) [1994] Culture and Value (revised edn) (trans. P. Winch). Oxford and Cambridge, MA : Blackwell.

Yamazumi, K., et al. (1997) Polyphony of Learning (in Japanese). Tokyo: Gakubunsha.

Yochi, Hiroshi (1990) "Self-Organization and Symbiosis through InformationCommunication" (in Japanese), JSICR Annual Report 1989: 41-52.

Yochi, Hiroshi (1992) "Cross-Cultural Understanding by Means of Epistemic Frameworks" (in Japanese), Joumal of the Japan Association for Philosophy of Science, Vol. 20 : 213218.

Yochi, Hiroshi (1994) "Human-Centered Systems and Mesarović's General Systems Theory" (in Japanese), Journal of the Japan Association for Philosophy of Science, Vol. 21 : 205211.

Yochi, Hiroshi (1995) "Systems as Epistemic Frameworks and Their Relations to Information-Communication" (in Japanese), JSICR Annual Report 1992 : 17-34. 